\title{
A methodology to quantify the aerobic and anaerobic sludge digestion performance for nutrient recycling in aquaponics
}

\author{
Boris Delaide ${ }^{(1)}$, Simon Goddek ${ }^{(2)}$, Karel J. Keesman ${ }^{(2)}$, M. Haissam M. Jijakli ${ }^{(1)}$ \\ (1) Université de Liège - Gembloux Agro-Bio Tech. Integrated and Urban Plant Pathology Laboratory. Avenue Maréchal Juin, \\ 13. BE-5030 Gembloux (Belgium).E-mail: boris.delaide@uliege.be \\ (2) Wageningen University \& Research. Biobased Chemistry \& Technology. P.O. Box 17. NL-6700 AA Wageningen \\ (The Netherlands).
}

Received 14 August 2017, accepted 16 April 2018; available online 8 May 2018.

This article is distributed under the terms and conditions of the CC-BY License (http://creativecommons.org/licenses/by/4.0)

Description of the subject. This research note presents a methodology to quantify the tilapia sludge digestion performance in aerobic and anaerobic reactors for aquaponic purpose. Both organic reduction and macro- and microelements mineralization performances were addressed.

Objectives. To set up an appropriate methodology to quantify sludge digestion performance in aquaponics. To describe the methodology and illustrate it with some results as example.

Method. Equations were adapted to quantify (1) the organic reduction performance in terms of chemical oxygen demand (COD) and total suspended solids (TSS) reduction, and (2) the nutrient recycling performance in terms of macro- and microelements mineralization.

Results. The equations were applied to data obtained from experimental aerobic and anaerobic reactors as example. Reactors were able to remove at least $50 \%$ of the TSS and COD input. The nutrient mineralization was consistent with a $10-60 \%$ range for all macro- and micronutrients.

Conclusions. The methodology provides explicit indicators on the sludge treatment performances for aquaponics. Treating aquaponic sludge onsite is promising to avoid sludge spillage, improve nutrient recycling and save water.

Keywords. Aquaponics, sustainable agriculture, aerobiosis, anaerobiosis, digesters, waste management, mineralization.

Une méthodologie pour quantifier les performances de digestion aérobie et anaérobie des boues, pour le recyclage des nutriments en aquaponie

Description du sujet. Cette note de recherche présente une méthodologie pour quantifier les performances de digestion des boues de tilapia dans les réacteurs aérobies et anaérobies en aquaponie. Les performances de réduction organique et de minéralisation des macro- et microéléments y sont étudiées.

Objectifs. Mettre en place une méthodologie appropriée pour quantifier les performances de digestion des boues en aquaponie. Décrire la méthodologie et l'illustrer avec quelques résultats à titre d'exemple.

Méthode. Des équations ont été adaptées pour quantifier (1) les performances de réduction organique en termes de réduction de la demande chimique en oxygène (DCO) et de solides totaux en suspension (MES), et (2) les performances de recyclage des nutriments en termes de minéralisation des macro- et microéléments.

Résultats. En guise d'exemple, les équations ont été appliquées aux données obtenues dans des réacteurs expérimentaux aérobies et anaérobies. Les réacteurs ont pu réduire au moins $50 \%$ de la DCO et de la MES. La minéralisation des éléments nutritifs était dans une fourchette de 10 à $60 \%$ pour tous les macro- et micronutriments.

Conclusions. La méthodologie a fourni des indicateurs explicites sur les performances de traitement des boues pour l'aquaponie. Le traitement des boues aquaponiques sur site est prometteur pour éviter le déversement des boues, améliorer le recyclage des nutriments et économiser l'eau.

Mots-clés. Aquaponie, agriculture durable, aérobiose, anaérobiose, digesteur, gestion des déchets, minéralisation. 


\section{INTRODUCTION}

Aquaponics is a major area of interest within the field of sustainable food production. Decoupled multi-loop aquaponics combines the multi-trophic food production systems of both recirculating aquaculture systems (RAS) and hydroponics (Goddek et al., 2016a). This concept leads to a sustainable production system as it re-utilizes RAS wastewater enriched in macronutrients (i.e. nitrogen $[\mathrm{N}]$, phosphorus $[\mathrm{P}]$, potassium $[\mathrm{K}]$, calcium $[\mathrm{Ca}]$, magnesium $[\mathrm{Mg}]$, and sulphur $[\mathrm{S}]$ ) and micronutrients (i.e. iron $[\mathrm{Fe}]$, manganese $[\mathrm{Mn}]$, zinc $[\mathrm{Zn}]$, copper $[\mathrm{Cu}]$, boron $[\mathrm{B}]$, and molybdenum $[\mathrm{Mo}]$ ) to fertilize the plants (Graber \& Junge, 2009; Licamele, 2009; Nichols \& Savidov, 2012; Turcios \& Papenbrock, 2014). Aquaponics usually operates at considerably low nutrient concentrations (Rakocy et al., 2004; Lund, 2014; Endut et al., 2016). However, it has been shown in experimental studies that complemented aquaponic water (i.e. addition of lacking nutrients) promotes plant growth compared to hydroponics (Delaide et al., 2016; Saha et al., 2016; Ru et al., 2017). In RAS, up to 50\% (in dry matter) of the feed ingested can be excreted as solids by fish (Chen et al., 1997). These solids are removed out of the system on a daily basis under the form of a sludge with a total solids (TS) of 0.4 to $12.3 \%$ and a chemical oxygen demand (COD)/TS ratio from 1.4 to 1.8 (Gebauer \& Eikebrokk, 2006; Mirzoyan et al., 2010; Verdegem, 2013). Since most of the nutrients that enter aquaponic systems via fish feed accumulate in the solid part of the RAS wastewater (Schneider et al., 2005; Neto \& Ostrensky, 2013), there is a high potential to recycle these nutrients (Jung \& Lovitt, 2011; Monsees et al., 2017). Reintroducing them into the aquaponic water via natural mineralization of fish sludge, while reducing the sludgy water spillage seems to be a promising way to improve the aquaponic system production performance. Hence, sludge mineralization could be a contributing factor to close the loop to a higher degree, to save water and thus lowering the environmental impact (Delaide et al., 2015).

In conventional water treatment methodology, the main objective of wastewater treatment is to obtain a clean effluent. The treatment performances are expressed in terms of removal of contaminants (e.g. total suspended solids [TSS], COD, N, P, etc.) out of the wastewater. The results are given in percentage indicating the effluent quality achieved (Techobanoglous et al., 2014). Several studies have provided quantitative evidence that a consistent proportion of COD and TSS can be removed by digesting the RAS wastewater under aerobic (AE), anaerobic (AN), and sequential AE-AN conditions (Chowdhury et al., 2010; Mirzoyan et al., 2010; Van Rijn, 2013). In opposite, the wastewater from fish in aquaponic systems is considered as a valuable fertilizer source and zero emission by closing the loop is aimed. So, on one hand the solid part discharged need to be minimized (i.e. organic reduction maximized) and on the other hand, the nutrient content in the effluent needs to be maximized (i.e. nutrient mineralization maximized). Therefore, the wastewater treatment performances need to be expressed not anymore in terms of contaminants removed but in contaminant reduction and nutrient mineralization ability.

Some authors already examined the release of $\mathrm{N}$ and $P$ from the fish sludge for a short period of time through in vitro batch experiments (Stewart et al., 2006; Conroy \& Couturier, 2010; Monsees et al., 2017). However, a deeper evaluation is required on the mineralization performance of all macro- and micronutrients that are beneficial to plants to validate the interest of aquaponic sludge treatment onsite. To date, there has been little conclusive evidence on mineralization performance of fish sludge under aerobic and anaerobic conditions. Moreover, experiments close to operational conditions (i.e., in continuous mode) are scarce in literature.

Therefore, the objective of this research note was to propose an adapted methodology to obtain explicit indicators to determine the performance of RAS wastewater treatment in the frame of aquaponics. New equations were set up to properly quantify the organic reduction performance, in terms of COD and TSS reduction, and the nutrient recycling performance, in terms of macro- and microelements mineralization, for aerobic and anaerobic sludge digestion. The methodology was applied to experimental reactors as an illustration. Hence, this short note presents exploratory results allowing to discuss the further development of such technique for nutrient recovery in aquaponics.

\section{MATERIALS AND METHODS}

\subsection{Determination of organic sludge reduction: COD oxidation and TSS reduction}

To determine the performance of RAS wastewater treatment as aerobic or anaerobic digestion in bioreactor, a mass balance approach needs to be achieved. The corresponding equation is as follows:

$$
\frac{d M}{d t}=\frac{F_{\text {in }}}{V} M_{\text {in }}-\frac{F_{\text {out }}}{V} M-r
$$

where $M$ is the mass (e.g. TSS or COD or a specific nutrient mass inside the reactor), $M_{i n}$ is the mass of the same compound in the effluent, $F$ is the flow rate (in $\mathrm{L} \cdot \mathrm{T}^{-1}$ ), $V$ the volume (in $\mathrm{L}^{3}$ ), and $r$ the reaction term (in $\left.\mathrm{M} \cdot \mathrm{T}^{-1}\right)$. 
To calculate the TSS reduction performance of the reactor $\left(\eta_{T S S}\right)$, i.e. the capacity to degrade solid matter into soluble particles, ions and gases, the equation (1) can be integrated from $t_{0}$ to $t_{f}$, as follows:

$$
\Delta T S S=T_{T S S i n}-T_{T S S o u t}-R_{T S S}
$$

where $\Delta T S S$ is the TSS inside the reactor at the end of the studied period $\left(\mathrm{t}_{\mathrm{f}}\right)$ minus the TSS inside the reactor at the beginning of the period $\left(\mathrm{t}_{0}\right), T_{\text {TSS out }}$ is the total TSS outflow, $T_{T S S \text { in }}$ is the total TSS inflow and $R_{T S S}$ the total reaction term (in $\mathrm{M}$ ).

The TSS reduction performance of the reactor was formulated as:

$$
\eta_{T S S}=\frac{R_{T S S}}{T_{T S S i n}}
$$

and by combining equation (2) in (3), the following equation can be used, to obtain the performance under the form of a percentage:

$$
\eta_{T S S}=100 \% \times\left(1-\frac{\Delta T S S+T_{\text {TSSout }}}{T_{T S S i n}}\right) .
$$

Similarly, the performance of the reactor in oxidizing COD $\left(\eta_{C O D}\right)$, i.e. the capacity to remove the COD from the wastewater input, follows from:

$$
\eta_{C O D}=100 \% \times\left(1-\frac{\Delta C O D+T_{C O D o u t}}{T_{C O D \text { in }}}\right)
$$

where $\triangle C O D$ is the COD inside the reactor at the end of the studied period minus the COD at the beginning of the period, $T_{C O D \text { out }}$ is the total COD outflow, and $T_{\text {COD in }}$ is the total COD inflow.

Thus, the reduction performance is all the better, with less solids discharged out of the loop, as COD and TSS accumulation and content inside the reactor and in the outflow are low.

\subsection{Determination of the nutrient recycling potential: macro- and microelement mineralization}

Based on the same mass balance equation, the nutrient mineralization performance of the treatment $\left(\eta_{N}\right)$, i.e. the conversion into soluble ions of the macro- and micronutrients present in the wastewater under undissolved forms, can be calculated using the following formula:

$$
\eta_{N}=100 \% \times\left(\frac{D N_{\text {out }}-D N_{\text {in }}}{T N_{\text {in }}-D N_{\text {in }}}\right)
$$

where $\eta_{N}$ is the nutrient recovery at the end of the studied period in percent, $D N_{\text {out }}$ is the total mass of dissolved nutrient in the outflow, $D N_{\text {in }}$ is the total mass of dissolved nutrient in the inflow, and $T N_{i n}$ is the total mass of dissolved plus undissolved nutrients in the inflow.

Thus, just like for organic reduction performances, the lower the accumulation and the content of undissolved nutrients in the reactor and in the outflow, the better the mineralization performance, and therefore the amount of nutrients recovered for aquaponic crop fertilization.

\subsection{Measurement of TSS, COD and nutrients masses}

Following the mass balance equations requirements, TSS, COD and nutrients masses have to be determined from each reactor input (i.e. fresh sludge) and output (i.e. effluents). The reactor content has to be sampled at the beginning and at the end of the experiment. The input, output and content of the reactor need to be perfectly mixed before sampling.

Reactor input and output should basically be sampled every time the reactors are fed with fresh sludge. TSS and COD shall be determined in triplicate following the APHA protocol (Eaton et al., 1998). For determination of the dissolved nutrients, the samples have to be $0.22 \mu \mathrm{m}$ filtrated and stored at $-20{ }^{\circ} \mathrm{C}$ prior to analysis. For determination of total nutrient content in sludge (i.e. dissolved and undissolved nutrients), the samples have to be dried at $70^{\circ} \mathrm{C}$ in an oven. Then pulverized and acid mineralized with $1: 1$ nitric $(65 \%)$ and perchloric acid (70\%). The samples composition in terms of macronutrient as $\mathrm{P}, \mathrm{K}, \mathrm{Ca}, \mathrm{Mg}$ and $\mathrm{S}$, and micronutrient as $\mathrm{Fe}, \mathrm{Mn}, \mathrm{Zn}, \mathrm{Cu}, \mathrm{B}$ and $\mathrm{Mo}$ can be determined with an inductively coupled plasma optical emission spectrometer (ICP-OES). The samples composition in $\mathrm{N}$ can be determined with the Kjeldahl method (i.e. directly from dried or fresh sludge) or with a spectrophotometer and the appropriate reagents. All the analysis should be carried out at least in triplicate.

\subsection{Description of an experiment where the methodology was applied}

Sludge digestion performances in terms of COD oxidation, TSS reduction and nutrient mineralization were analyzed in an aerobic reactor (AER) and an anaerobic reactor (ANR) (Figure 1). The sludge was derived from an aquaponic system situated at Zürich University of Applied Sciences (ZHAW) 

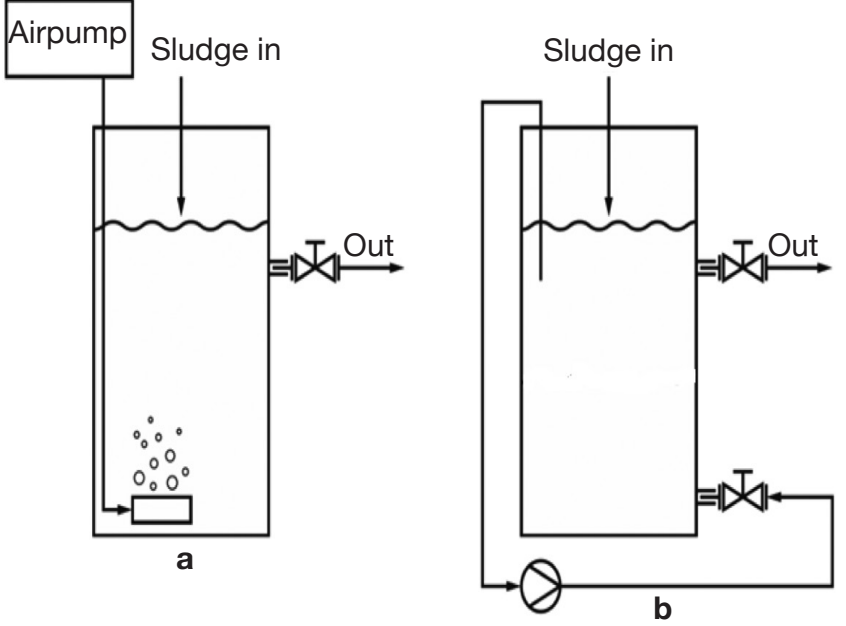

Figure 1. a. aerobic digester, constantly aerated and mixed - digesteur aérobie, constamment aéré et mélangé; b. anaerobic digester, in order to assure a slow mixing of the sludge, a constant up flow velocity of $0.9 \mathrm{~m} \cdot \mathrm{h}^{-1}$ was applied by a small pump recirculating constantly the top water of the reactor into the bottom inlet. Both reactors were $30 \mathrm{~cm}$ in diameter and $70 \mathrm{~cm}$ high with an operating volume of 451 - digesteur anaérobie, afin d'assurer un mélange lent des boues, une vitesse ascendante constante de $0,9 \mathrm{~m} \cdot \mathrm{h}^{-1}$ a été maintenue grâce à une pompe qui recirculait constamment l'eau de la surface du réacteur vers l'entrée située au fond. Les deux réacteurs avaient un diamètre de $30 \mathrm{~cm}$ et une hauteur de $70 \mathrm{~cm}$ pour un volume effectif de $45 \mathrm{l}$.

loaded with tilapia (Oreochromis niloticus L.). The sludge characteristics are presented in table 1. At the beginning of the experiment, the AER and the ANR were inoculated with 1.51 of digested sludge, from another experimental AER and ANR (Goddek et al., 2016b), respectively, to introduce microorganisms that were adapted to the growing conditions. To work in a semi-continuous mode, reactors were manually batchfed three times per week with fresh sludge. A hydraulic retention time (HRT) of 15 days was applied to both reactors, since the same volume of water (i.e. clear decanted effluent) was discharged from the outlets of each reactor. The reactors were operated for 42 days. No solids were discharged during the experiment, except a negligible amount for sampling purposes. The temperature inside both reactors was constantly held at $28{ }^{\circ} \mathrm{C}$ using an aquarium heater with a thermostat. To check the operational stability of the temperature, $\mathrm{pH}$, electroconductivity, redox potential, and the dissolved oxygen were measured in fresh sludge input, inside the reactors, and in the reactor effluents at each batch-fed time with a portable multi-parameter meter (HQ40d, HACH Lange, Loveland, CO, USA). TSS, $\mathrm{COD}$ and nutrient masses were determined following

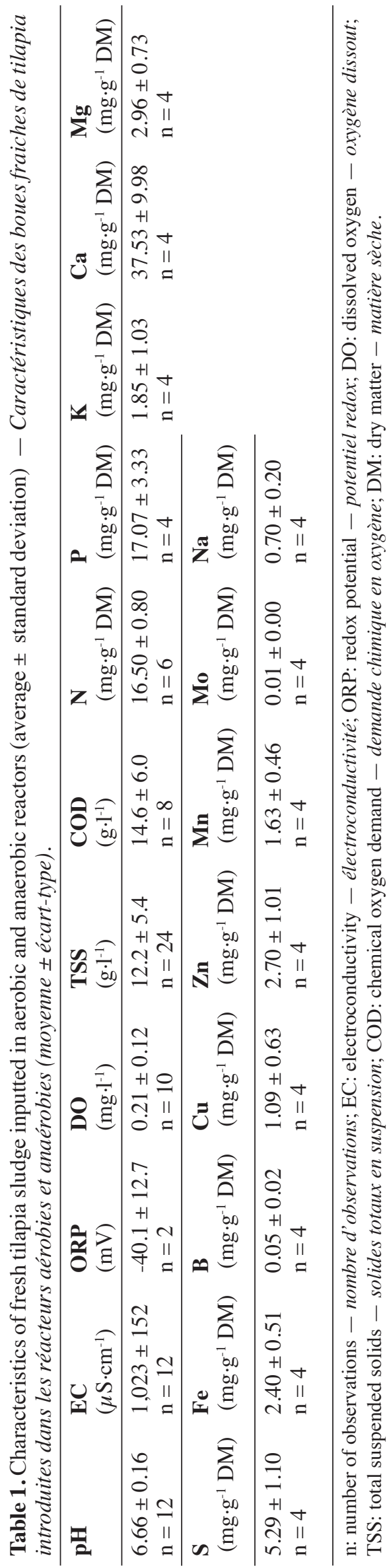


the sampling and measurement methodology described above (2.3.). Samples nutrient content were determined with ICP-OES (5100 VDV ICP-OES, Agilent Technologies, Santa Clara, CA, USA). This device gave a measure with a coefficient of variation of $0.51 \%$. The total Kjeldahl nitrogen (TKN) was analyzed with a distillation unit (B-324, Buchi, Flawil, Switzerland). All the analyses were carried out in triplicate.

\section{RESULTS AND DISCUSSION}

\subsection{TSS reduction and COD oxidation}

The methodology was applied to the experiment described above. The performances of the AER and ANR reactor were calculated for one repetition with the appropriate equations and the results are presented in table 2. The TSS reduction performance after 42 days for ANR and AER was 49.0 and $60.8 \%$, respectively (Table 2). This shows an $11.8 \%$ performance difference between ANR and AER. With respect to COD, the oxidation performance was $56.9 \%$ and 68.5 for ANR and AER showing an $11.6 \%$ performance difference between AER and ANR.

Regarding literature, aerobic digestion seemed to be more performant for COD oxidation and TSS reduction on short period (Chen et al., 1997; Najafpour et al., 2006; Gao et al., 2011; Tchobanoglous \& Burton, 2014). However, experiments realized on short period give only an indication on the easily degradable sludge compounds. The recalcitrant particles (i.e. carbohydrates as phenols, lignin, etc.) take a long time to be degraded (van Rijn et al., 1995). Under aerobic (AE) conditions, the microorganism growth is much higher than under anaerobic (AN) conditions and a considerable higher part of the sludge is converted into new biomass that accumulates in the reactor instead of leaving it as degraded organic matter as in AN conditions (Van Lier et al., 2008). Therefore, the highest performance of sludge reduction reported in literature is found in AN digestion in long-term experiments with a long sludge retention time (SRT) (Mirzoyan et al., 2010; Mirzoyan \& Gross, 2013). Under these conditions, the recalcitrant carbohydrates that were contained in the sludge might eventually have been converted into volatile fatty acids (VFAs), carbon dioxide $\left(\mathrm{CO}_{2}\right)$, and methane $\left(\mathrm{CH}_{4}\right)$, and thus left the reactor. Anaerobic sludge blanket reactor (UASB) technology seems to be the most interesting option to treat aquaponic sludge onsite. Anaerobic sludge blanket reactors have the advantage to consume less power to run (no aeration needed, lower operational cost) and the $\mathrm{CH}_{4}$ produced can be a source of thermal and electric energy for the system (Van Lier et al., 2008).
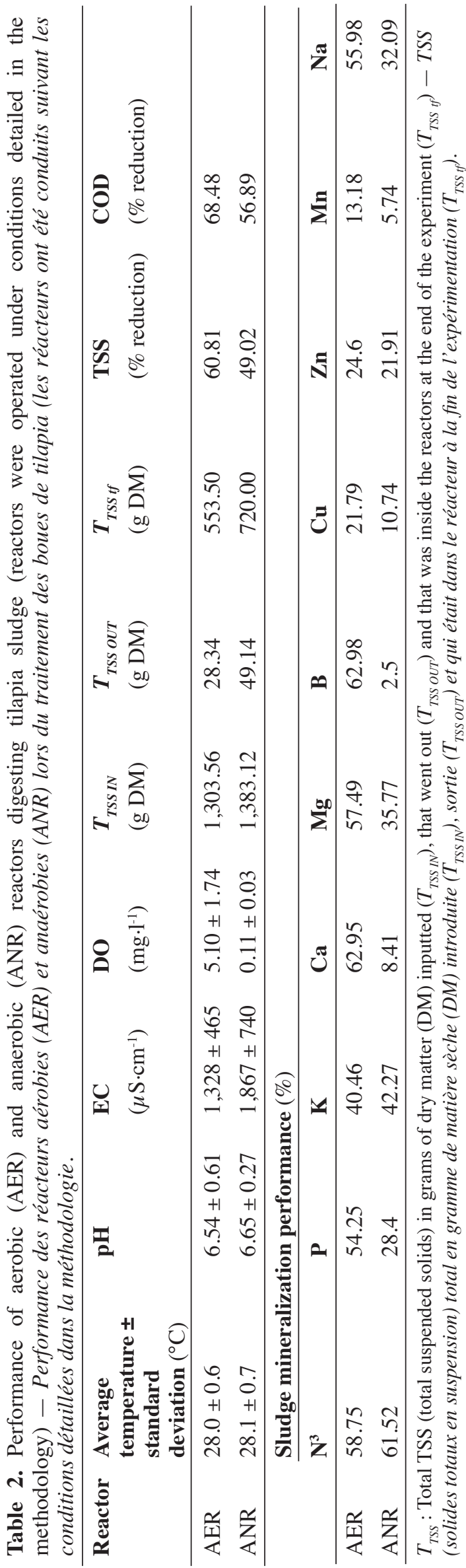


\subsection{Sludge mineralization}

The AER showed better mineralization performance for most of the nutrients except for $\mathrm{N}$ and $\mathrm{K}$. Indeed, $\mathrm{P}, \mathrm{Ca}, \mathrm{Mg}$ and $\mathrm{B}$ were in a range of 54.2 to $63.0 \%$ for AER while 2.5 to $35.8 \%$ for ANR. Copper, $\mathrm{Zn}$ and Mn were in a range of 13.2 to $24.6 \%$ for AER while 5.7 to $21.9 \%$ for ANR (Table 2). Unfortunately, due to missing data we were not able to determine the mineralization performance of $\mathrm{S}, \mathrm{Fe}$ and Mo. Since assessing mineralization performance is quite innovative, there are not many studies in literature to confront our results. Jung and Lovitt (Jung \& Lovitt, 2011) studied nutrient leaching from trout sludge during AN digestion in broths and their observed results for $\mathrm{P}, \mathrm{Mg}, \mathrm{K}$, and $\mathrm{Ca}$ are in the same range as in this study (i.e., $7-66 \%$ ).

\section{CONCLUSIONS}

The methodology proposed was applied to an experiment of tilapia sludge digestion with AER and ANR. Explicit indicators on the treatments performances were obtained making this methodology suitable for aquaponics. AER and ANR were able to reduce at least $50 \%$ of the TSS and COD of the sludge input. Also, the sludge mineralization in both treatments was consistent with a $10-60 \%$ range for all macro- and micronutrients. This makes AE and AN digestion a promising way of treating aquaponic sludge onsite in order to reduce aquaponic sludge discharge, recycle more nutrients and save water. Especially, anaerobic treatment with long SRT and technology as UASB should be deeper explored for aquaponic sludge treatment with a special focus on its mineralization performance.

\section{Bibliography}

Chen S.L., Coffin D.E. \& Malone R.F., 1997. Sludge production and management for recirculating aquacultural systems. J. World Aquacult. Soc., 28(4), 303-315.

Chowdhury P., Viraraghavan T. \& Srinivasan A., 2010. Biological treatment processes for fish processing wastewater. A review. Bioresour. Technol., 101(2), 439449.

Conroy J. \& Couturier M., 2010. Dissolution of minerals during hydrolysis of fish waste solids. Aquaculture, 298(3-4), 220-225.

Delaide B. et al., 2015. Challenges of sustainable and commercial aquaponics. Sustainability, 7(4), 4199-4224.

Delaide B. et al., 2016. Lettuce (Lactuca sativa L. var. Sucrine) growth performance in complemented aquaponic solution outperforms hydroponics. Water (Switzerland), 8(467).

Eaton A.D. et al., 1998. Standard methods for the examination of water and wastewater. Washington, DC, USA: American Public Health Association.

Endut A. et al., 2016. Balancing of nutrient uptake by water spinach (Ipomoea aquatica) and mustard green (Brassica juncea) with nutrient production by African catfish (Clarias gariepinus) in scaling aquaponic recirculation system. Desalin. Water Treat., 57(60).

Gao D., Liu L., Liang H. \& Wu W.-M., 2011. Aerobic granular sludge: characterization, mechanism of granulation and application to wastewater treatment. Crit. Rev. Biotechnol., 31(2), 137-152.

Gebauer R. \& Eikebrokk B., 2006. Mesophilic anaerobic treatment of sludge from salmon smolt hatching. Bioresour. Technol., 97(18), 2389-2401.

Goddek S. et al., 2016a. Navigating towards decoupled aquaponic systems: a system dynamics design approach. Water (Switzerland), 8(7).

Goddek S. et al., 2016b. The effect of anaerobic and aerobic fish sludge supernatant on hydroponic lettuce. Agronomy, 6(2), 37.

Graber A. \& Junge R., 2009. Aquaponic systems: nutrient recycling from fish wastewater by vegetable production. Desalination, 246(1-3), 147-156.

Jung I.S. \& Lovitt R.W., 2011. Leaching techniques to remove metals and potentially hazardous nutrients from trout farm sludge. Water Res., 45(18), 5977-5986.

Licamele J.D., 2009. Biomass production and nutrient dynamics in an aquaponics system. $\mathrm{PhD}$ thesis: The University of Arizona (USA).

Lund J., 2014. Aquaculture effluents as fertilizer in hydroponic cultivation. Uppsala, Sweden: Swedish University of Agricultural Sciences.

Mirzoyan N., Tal Y. \& Gross A., 2010. Anaerobic digestion of sludge from intensive recirculating aquaculture systems: review. Aquaculture, 306(1-4), 1-6.

Mirzoyan N. \& Gross A., 2013. Use of UASB reactors for brackish aquaculture sludge digestion under different conditions. Water Res., 47(8), 2843-2850.

Monsees H. et al., 2017. Potential of aquacultural sludge treatment for aquaponics: evaluation of nutrient mobilization under aerobic and anaerobic conditions. Aquacult. Environ. Interact., 9, 9-18.

Najafpour G.D., Zinatizadeh A.A.L. \& Lee L.K., 2006. Performance of a three-stage aerobic RBC reactor in food canning wastewater treatment. Biochem. Eng. J., 30(3), 297-302.

Neto R.M. \& Ostrensky A., 2013. Nutrient load estimation in the waste of Nile tilapia Oreochromis niloticus (L.) reared in cages in tropical climate conditions. Aquacult. Res., 46(6), 1309-1322.

Nichols M.A. \& Savidov N.A., 2012. Aquaponics: a nutrient and water efficient production system. Acta Hortic., 947, 129-132. 
Rakocy J.E., Bailey D.S., Shultz R.C.\& Thoman E.S., 2004. Update on tilapia and vegetable production in the UVI aquaponic system. New dimensions on farmed tilapia. In: Proceedings from the $6^{\text {th }}$ International Symposium on Tilapia in Aquaculture, Manila, Philippines, 1-15.

$\mathrm{Ru}$ D. et al., 2017. Improvement of aquaponic performance through micro- and macro-nutrient addition. Environ. Sci. Pollut. Res. Int., 24(19), 16328-16335.

Saha S., Monroe A. \& Day M.R., 2016. Growth, yield, plant quality and nutrition of basil (Ocimum basilicum L.) under soilless agricultural systems. Ann. Agric. Sci., 61(2), 181-186.

Schneider O., Sereti V., Eding E.H. \& Verreth J.A.J., 2005. Analysis of nutrient flows in integrated intensive aquaculture systems. Aquacult. Eng., 32(3-4), 379-401.

Stewart N.T., Boardman G.D. \& Helfrich L.A., 2006. Characterization of nutrient leaching rates from settled rainbow trout (Oncorhynchus mykiss) sludge. Aquacult. Eng., 35(2), 191-198.

Tchobanoglous G. \& Burton F.L., 2014. Wastewater engineering: treatment, disposal and reuse. $5^{\text {th }}$ ed. New York, NY, USA: McGraw-Hill, 1819.
Turcios A.E. \& Papenbrock J., 2014. Sustainable treatment of aquaculture effluents. What can we learn from the past for the future ? Sustainability, 6(2), 836-856.

Van Lier J.B., Mahmoud N. \& Zeeman G., 2008. Anaerobic wastewater treatment. In: Henze M., van Loosdrecht M.C.M., Ekama G.A. \& Brdjanovic D., eds. Biological wastewater treatment : principles, modelling and design. London: IWA Publishing, 401-442.

Van Rijn J., 2013. Waste treatment in recirculating aquaculture systems. Aquacult. Eng., 53, 49-56.

Van Rijn J., Fonarev N. \& Berkowitz B., 1995. Anaerobic treatment of intensive fish culture effluents: digestion of fish feed and release of volatile fatty acids. Aquaculture, 133(1), 9-20.

Verdegem M.C.J.,2013. Nutrient discharge from aquaculture operations in function of system design and production environment. Rev. Aquacult., 5(3), 158-171. 